\title{
Permissive tolerance of the patent ductus arteriosus may increase the risk of Chronic Lung Disease
}

\author{
Joseph W Kaempf' \\ Robert Huston ${ }^{2}$ \\ YingXing $\mathrm{Wu}^{\prime}$ \\ Andrew J Kaempf' \\ Lian Wang' \\ Gary Grunkemeier ${ }^{\prime}$ \\ Rebecca Mischel $^{2}$ \\ Howard Cohen ${ }^{3}$ \\ Bret Freitag ${ }^{4}$
}

'Providence St Vincent Medical

Center, Portland, OR, ${ }^{2}$ Randall

Children's Hospital at Legacy Emanuel,

Portland, OR, ${ }^{3}$ Salem Hospital, Salem,

OR, ${ }^{4}$ Legacy Salmon Creek Hospital,

Vancouver, WA, USA

\section{Video abstract}

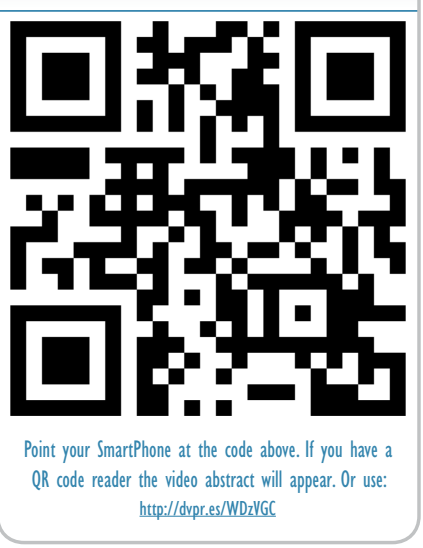

Correspondence: Joseph W Kaempf Pediatrix Medical Group, Providence St Vincent Medical Center, 9205 SW Barnes Road, Portland, OR 97225, USA Tel +I 5032167383

Email joseph_kaempf@pediatrix.com
This article was published in the following Dove Press journal:

Research and Reports in Neonatology

7 March 2013

Number of times this article has been viewed

Purpose: Because early closure therapies of the patent ductus arteriosus (PDA) have not been shown to confer benefit to premature infants, the authors' four neonatal intensive care units adopted a less aggressive PDA management protocol.

Study design: A before-after investigation in infants with PDAs born 501-1500 g. Era 1 (January 2005 to December 2007) featured traditional management with indomethacin and/or surgical ligation used early to close PDAs; Era 2 (January 2008 to June 2009) featured fluid restriction and watchful waiting for PDA closure, limiting indomethacin or surgical ligation to only those infants with large PDAs needing significant respiratory support.

Results: Era 2 infants $(n=129$, mean \pm standard deviation $27 \pm 2$ weeks) received less and later indomethacin and less Day 1-28 total fluids as compared to Era 1 infants $(n=240$, mean \pm standard deviation $27 \pm 2$ weeks). The Chronic Lung Disease (CLD) rate was higher in Era $2(48 \%$ versus $34 \%, P<0.01)$ as was the combined outcome of Death after Day 7 or CLD $(57 \%$ versus $42 \%, P<0.01)$. Multiple regression analysis showed Era 2 birth was a predictor of CLD. However, Poisson regression analysis determined the predictors of all seven major Vermont Oxford Network morbidities were earlier gestational age, lower birth weight, and male gender, not the era of birth. Significantly more infants were discharged home with PDAs in Era 2.

Conclusion: Permissive tolerance of PDAs may increase the risk of CLD and Death after Day 7 or CLD but is not associated with significant changes in other Vermont Oxford Network morbidities.

Keywords: premature infant, indomethacin, surgical ligation, quality improvement

\section{Introduction}

Patent ductus arteriosus (PDA) is diagnosed in 37\% of premature infants born 501-1500 g, and is apparently thought morbid by most neonatologists since $80 \%$ of these PDA neonates receive indomethacin or ibuprofen and 19\% undergo surgical ligation. ${ }^{1}$ Bose and Laughon ${ }^{2}$ and Benitz ${ }^{3,4}$ have emphasized the lack of convincing evidence to support the common practice of early aggressive closure therapy and caution us to be skeptical because: (a) a causal relationship between the PDA and other neonatal intensive care unit (NICU) morbidities is lacking, and (b) there has never been a randomized controlled trial (RCT) with a true control group (no or substantially delayed pharmacologic or surgical treatment).

Early reports of modest success in NICU quality improvement (QI) projects have stoked the enthusiasm of attaining better outcomes safely and at lower cost. ${ }^{5}$ Some believed in what was essentially a business and manufacturing model of QI to be wholly applicable to medical care. ${ }^{6}$ The promise of QI has disappointed because meaningful, 
sustained gains in quality, safety, and efficiency have been difficult to document. ${ }^{7}$ For example, two large-scale collaborative QI efforts attempted to implement comprehensive evidence-based practices to reduce Chronic Lung Disease (CLD). In both the university setting and community NICUs, time- and effort-intensive QI efforts have demonstrably failed to reduce the rate of CLD. ${ }^{8,9}$

The purpose of this investigation is to link the two themes above to help meet the elusive 21 st century goals of quality, safety, and affordability. ${ }^{10}$ This study describes the attempt to both: (a) manage the PDA in a less aggressive, evidencebased manner that would minimize unproven therapies and optimize overall morbidity, and (b) navigate the uncertainties, provider vagaries, and unexpected outcomes inherent to QI projects. As previously described, the authors' initial permissive PDA QI effort from a single NICU found a possible increase in CLD and/or Mortality. ${ }^{11}$ Therefore, the current analysis was expanded to include three more NICUs to both increase the number of study infants with PDAs and learn from the complexities of multiple-site QI efforts.

\section{Study design}

Approval for this investigation was obtained from the institutional review board of each hospital. The four participating NICUs are staffed by 21 neonatologists who engage in group QI projects and data sharing, with some overlap of staffing. All infants born 501-1500 g who were admitted to the NICU, diagnosed with a PDA, and survived at least 7 days were included for analysis. No deaths before 7 days were thought to be due to a PDA. This investigation was conducted concurrently as a QI project at all four NICUs during the exact same time period; no NICU was aware of the other NICUs' cumulative outcomes. The definition of gestational age and all standard morbidities were taken from Vermont Oxford Network's (VON) manual of operations. ${ }^{12}$ Specifically, a PDA was diagnosed in both eras if an infant had evidence of a left-to-right shunt as documented by a systolic murmur, hyperdynamic precordium, bounding pulses, wide pulse pressure, increased pulmonary vasculature or cardiomegaly, and/or increased oxygen administration, or echocardiographic demonstration of a PDA with a left-toright shunt. ${ }^{12}$ CLD was defined as any supplemental oxygen use at 36 weeks gestational age. ${ }^{12}$ Nasal continuous positive airway pressure (NCPAP) was used in both eras as the primary means of respiratory support in any infant with apnea or a need for supplemental oxygen. Mechanical ventilation and/or surfactant therapy were employed only if the infant failed NCPAP (oxygen need $>40 \%$, significant apnea).
The control period (ie, Era 1) was January 2005 to December 2007, during which respiratory and PDA management was relatively uniform. Prophylactic indomethacin was not given and no specific fluid restriction regimen was recommended. Infants with PDAs were treated relatively early with indomethacin if they received supplemental oxygen and/or any level of NCPAP or mechanical ventilation. One course of indomethacin dose was usually $0.2 \mathrm{mg} / \mathrm{kg}$ given every 12-24 hours for three doses. Ibuprofen was not used in either era. Surgical ligation was used for PDAs not responsive to indomethacin.

After multiple group discussions among the staff at the four participating NICUs, which included a comprehensive review of the PDA literature and local VON outcomes data, a permissive, less aggressive PDA approach was adopted for Era 2 (January 2008 to June 2009). This time interval was prospectively chosen to be adequate to detect important clinical differences in outcomes but not so long as to potentially put an undue number of infants at risk for significant morbidities related to untreated PDAs. The Era 2 PDA management guidelines emphasized NCPAP as the primary means of respiratory support, recommended modest fluid restriction, and encouraged watchful waiting for spontaneous PDA closure. A PDA was considered for more aggressive therapy only if adequate oxygenation and ventilation could not be maintained on NCPAP at 5-6 cm water pressure, an increasing oxygen need $>40 \%$, or if the infant could not be weaned from mechanical ventilation. At that point an echocardiogram was obtained and only those infants with significantly large PDAs were treated with indomethacin (size $>2-3 \mathrm{~mm}$, a left-to-right shunt, and left atrial and left ventricular enlargement). Biomarkers such as B-type natriuretic peptide were not used in either era. Echocardiograms after therapy were done at the clinician's discretion based upon physical findings and the clinical course. Surgical ligation was used if the symptomatic PDA was unresponsive to indomethacin. Although not a rigid practice parameter, physicians were urged to follow these guidelines knowing that a before-after observational study was being conducted. Identical criteria were used in both eras to diagnose a PDA (VON criteria). Oxygen saturation targeting with pulse oximetry was similar in both eras: $86 \%-94 \%$ for any infant receiving supplemental oxygen. In both eras, the hemoglobin level was generally maintained $\geq 12 \mathrm{~g} / \mathrm{dL}$ if an infant was on a ventilator, $\geq 9-10 \mathrm{~g} / \mathrm{dL}$ if on NCPAP, and $\geq 8 \mathrm{~g} / \mathrm{dL}$ in all others.

For comparison of categorical variables, Chisquared or Fisher's exact tests were used. For continuous variables, Student's $t$-tests or Mann-Whitney $U$ tests were used where applicable. The Likelihood Ratio Test was used to 
test the NICU VON morbidity rates ratio. Stepwise Poisson regression with the NICU center as a random effect was used to determine the predictors for multiple NICU morbidities, with length of stay as the offset variable. Stepwise logistic regression was used to determine the predictors of CLD. The era of birth was forced into the models to evaluate its effect when adjusted by the predictors. Statistical analysis was performed using PASW Statistics 17 (SPSS Inc, Chicago, IL, USA), and R 2.11 (http://www.R-project.org).

\section{Results}

Of all infants born 501-1500 g, 36\% and 33\% were diagnosed with a PDA and survived the first week of life in Era 1 and Era 2, respectively, and only PDA infants were included in the analysis. Providence St Vincent Medical Center contributed $57 \%$ of the study infants, ${ }^{11}$ Randall Children's Hospital 32\%, Salem Hospital 8\%, and Legacy Salmon Creek 3\%. Table 1 describes the study infants and a profile of the clinical management. Era 2 infants received less Day 1-28 total fluids, less and later indomethacin, and later surgical ligation $(P<0.001)$. There were no significant differences in surfactant use, supplemental oxygen, or mechanical ventilation days; however, NCPAP was used more in Era $2(P<0.02)$ (Table 2$)$.

Table I Clinical characteristics, total fluids, indomethacin use, and surgical ligation in Era I versus Era 2

\begin{tabular}{|c|c|c|c|}
\hline & Era I & Era 2 & $P$-value \\
\hline Number of infants & 240 & 129 & \\
\hline $\begin{array}{l}\text { Postmenstrual age, weeks } \\
\text { (mean } \pm \mathrm{SD})\end{array}$ & $27.4 \pm 2.0$ & $27.3 \pm 2.1$ & 0.54 \\
\hline Birth weight, g (mean $\pm \mathrm{SD}$ ) & $989 \pm 229$ & $951 \pm 274$ & 0.16 \\
\hline Race & & & 0.70 \\
\hline Caucasian & $73 \%$ & $69 \%$ & \\
\hline Hispanic & $11 \%$ & $16 \%$ & \\
\hline Asian & $10 \%$ & $9 \%$ & \\
\hline African American & $4 \%$ & $5 \%$ & \\
\hline Other & $1 \%$ & $2 \%$ & \\
\hline Male gender & $55 \%$ & $47 \%$ & 0.12 \\
\hline \multicolumn{4}{|c|}{ Daily total fluids, IV plus oral, mL/kg/day (mean $\pm \mathrm{SD}$ ) } \\
\hline Day I-28 & $142 \pm 11$ & $132 \pm 9$ & $<0.001$ \\
\hline Week I & $127 \pm 20$ & $115 \pm 14$ & $<0.001$ \\
\hline Week 2 & $144 \pm 15$ & $134 \pm 12$ & $<0.001$ \\
\hline Week 3 & $148 \pm 15$ & $139 \pm 14$ & $<0.001$ \\
\hline Week 4 & $151 \pm 12$ & $|4| \pm 14$ & $<0.001$ \\
\hline Indomethacin given & $79 \%$ & $26 \%$ & $<0.001$ \\
\hline Second course of indomethacin & $34 \%$ & $12 \%$ & $<0.001$ \\
\hline $\begin{array}{l}\text { Day of life at first dose } \\
\text { (median [range]) }\end{array}$ & $4(1-18)$ & $13(1-32)$ & $<0.001$ \\
\hline Surgical ligation & $44 \%$ & $38 \%$ & 0.27 \\
\hline $\begin{array}{l}\text { Day of life at surgical ligation } \\
\text { (median [range]) }\end{array}$ & II (2-74) & $20(5-7 I)$ & $<0.001$ \\
\hline
\end{tabular}

Abbreviations: IV, intravenous; SD, standard deviation.
Table 2 Respiratory support in Era I versus Era 2

\begin{tabular}{llll}
\hline & Era I & Era 2 & P-value \\
\hline Number of infants & 240 & 129 & \\
Surfactant & $79 \%$ & $79 \%$ & 0.98 \\
$\begin{array}{l}\text { Supplemental oxygen, days } \\
\text { (median [range]) }\end{array}$ & 38 & 42 & 0.53 \\
$\begin{array}{l}\text { Required nasal continuous } \\
\text { positive airway }\end{array}$ & $9-129)$ & $(0-115)$ & \\
Nasal continuous positive airway & 22 & $91 \%$ & 0.22 \\
$\begin{array}{l}\text { pressure, days (median [range])* } \\
\text { Required any mechanical ventilation }\end{array}$ & $(\mathrm{I}-67)$ & 26 & 0.02 \\
$\begin{array}{l}\text { Mechanical ventilation, days } \\
\text { (median [range])* }\end{array}$ & 7 & $81 \%$ & 0.67 \\
Steroids for Chronic Lung Disease & $8 \%$ & $4 \%$ & 0.29 \\
\hline
\end{tabular}

Note: *If respiratory support needed.

Table 3 lists the principle outcomes of the investigation, ie, the attempt to gauge the overall VON morbidity profile (CLD, grade III/IV intraventricular hemorrhage, periventricular leukomalacia, stage III/IV retinopathy of prematurity, necrotizing enterocolitis, spontaneous intestinal perforation, and any late infection - all weighted equally). CLD (34\%$48 \%$ ) and the combined outcome of Mortality after Day 7 or CLD (42\%-57\%) were both significantly increased in Era $2(P<0.01)$. There were no other significant differences in morbidities, number of morbidities per infant, or the Likeli-

Table 3 Vermont Oxford Network clinical outcomes in Era I versus Era 2

\begin{tabular}{|c|c|c|c|}
\hline & Era I & Era 2 & $P$-value \\
\hline Number of infants & 240 & 129 & \\
\hline Mortality after Day 7 & $9 \%(22)$ & $13 \%(17)$ & 0.23 \\
\hline Chronic Lung Disease & $34 \%(78 / 230)$ & $48 \%(59 / 122)$ & $<0.0$ I \\
\hline Mortality after Day 7 or & $42 \%(100)$ & $57 \%(73)$ & $<0.01$ \\
\hline $\begin{array}{l}\text { Grade III/IV intraventricular } \\
\text { hemorrhage }\end{array}$ & $10 \%(24)$ & $8 \%(10)$ & 0.48 \\
\hline Periventricular leukomalacia & $4 \%(9 / 235)$ & $2 \%(2 / 128)$ & 0.23 \\
\hline Necrotizing enterocolitis & $8 \%(19)$ & $10 \%(13)$ & 0.48 \\
\hline $\begin{array}{l}\text { Spontaneous intestinal } \\
\text { perforation }\end{array}$ & $4 \%(9)$ & $4 \%(5)$ & 0.95 \\
\hline Late onset sepsis & $13 \%(3 \mid)$ & $15 \%(19)$ & 0.63 \\
\hline Retinopathy of prematurity & & & 0.26 \\
\hline None & $58 \%(118 / 202)$ & $51 \%(60 / 117)$ & \\
\hline Stage I/II & $31 \%(63 / 202)$ & $40 \%(47 / 117)$ & \\
\hline Stage III/IV & $10 \%(21 / 202)$ & $9 \%(10 / 117)$ & \\
\hline $\begin{array}{l}\text { Total length of stay, } \\
\text { days (mean } \pm S D \text { ) }\end{array}$ & $68 \pm 29$ & $73 \pm 30$ & 0.07 \\
\hline $\begin{array}{l}\text { Number of NICU } \\
\text { morbidities/infant }\end{array}$ & 0.8 & 0.9 & 0.12 \\
\hline $\begin{array}{l}\text { Morbidity rates per day } \\
\text { of NICU stay }\end{array}$ & 0.01 & 0.01 & $0.56 *$ \\
\hline
\end{tabular}


hood Ratio Test for Poisson morbidity counts. To further examine the possible impact of permissive PDA management, Figure 1 shows the percentage of infants in each era that had none or at least one of the seven major VON morbidities. There was no indication that the Era 2 management improved or worsened the overall morbidity burden.

Table 4 shows the logistic regression predictors of CLD to be earlier postmenstrual age, lower birth weight, and Era 2 birth. However, Poisson regression count for the number of major VON morbidities shows that earlier postmenstrual age, lower birth weight, and male gender to be predictive of adverse outcomes, not the era of birth (Table 5). Significantly more infants were discharged home with a persistent PDA in Era $2(29 / 129 ; 22 \%)$ than in Era $1(13 / 240$; $5 \%)(P<0.001)$. Fourteen percent $(4 / 29)$ of the persistent PDAs in Era 2 required later coiling versus $15 \%(2 / 13)$ in Era $1(P>0.99)$.

\section{Discussion}

This QI project, a before-after observational study in two distinct time periods, involving four NICUs has attempted to implement an evidence-based consensus protocol that has facilitated less aggressive PDA management and is the largest investigation of its kind to date. From this study we learned: (a) permissive tolerance of significant PDAs may increase the risk of CLD and Mortality after Day 7 or CLD, (b) the overall NICU morbidity burden including all the principle VON diagnoses was not changed by less aggressive PDA management, and (c) the context in which potentially

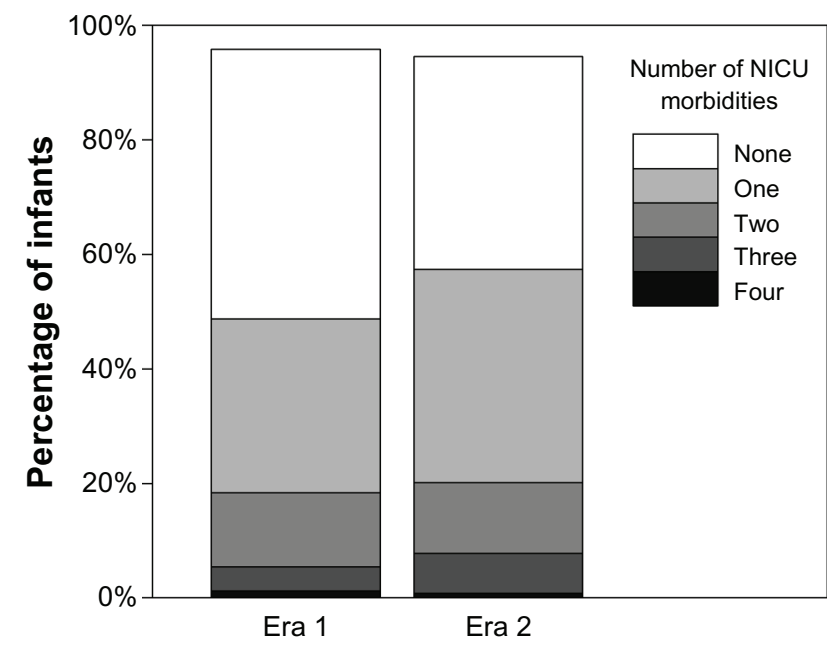

Figure I The percentage of infants with none or at least one of the seven major Vermont Oxford Network morbidities in Era I versus Era 2. Chronic Lung Disease, grade III/IV intraventricular hemorrhage, periventricular leukomalacia, stage III/ IV retinopathy of prematurity, necrotizing enterocolitis, spontaneous intestinal perforation, and any late infection all weighted equally.

Abbreviation: NICU, neonatal intensive care unit.
Table 4 Predictors identified by logistic regression for Chronic Lung Disease

\begin{tabular}{|c|c|c|}
\hline $\begin{array}{l}\text { Predictors for Chronic } \\
\text { Lung Disease }\end{array}$ & $\begin{array}{l}\text { Odds ratio } \\
(95 \% \mathrm{Cl})\end{array}$ & $P$-value \\
\hline Postmenstrual age (by week) & $0.8 \mathrm{I}(0.68-0.97)$ & 0.02 \\
\hline Birth weight (by $100 \mathrm{~g}$ ) & $0.76(0.66-0.87)$ & $<0.001$ \\
\hline Era 2 & I.77 (I.07-2.9|) & 0.03 \\
\hline
\end{tabular}

Abbreviation: $\mathrm{Cl}$, confidence interval.

better practices are implemented contain sizable human factors related to physician perception and skill, NICU decisionmaking culture, and unmeasured biologic variables. Based on this QI experience, Table 6 shows our newly revised 2012 PDA management protocol. This is believed to be a balanced sensibility of: (a) minimizing unproven PDA therapies, (b) improving clinical acumen thought to be necessary to prevent the premature infant from excessive exposure to prolonged, significant PDA physiology, and (c) heightened clinician awareness of rational QI methodology.

RCTs related to PDA management have generally compared prophylactic or early intervention therapies with moderately early interventions, and have not answered the primary question of whether PDAs need pharmacologic or surgical treatment in the first place. ${ }^{2,3}$ Recently, Sosenko et al conducted a small RCT comparing early ibuprofen treatment of PDAs (Day 3) with expectant management. Fewer infants in the expectant group required ibuprofen and the initiation of treatment was delayed to Day 11. Of interest, there were no significant differences in the surgical ligation rate or a broad array of NICU morbidities. ${ }^{13}$

Conducting and publishing QI efforts is an important task to promote transparency and disseminate knowledge as to why interventions succeed or fail, and if rigorous pre- and postintervention data collection are analyzed, then bias and confounders are reduced. ${ }^{14}$ Berwick has highlighted the complex challenge of improving the science of QI while accounting for

Table 5 Predictors identified by Poisson regression for the number of neonatal intensive care unit morbidities (Chronic Lung Disease, grade III/IV intraventricular hemorrhage, periventricular leukomalacia, stage III/IV retinopathy of prematurity, necrotizing enterocolitis, spontaneous intestinal perforation, and any late infection), all weighted equally

\begin{tabular}{lll}
\hline Predictors for multiple & $\begin{array}{l}\text { Rate ratio } \\
\mathbf{( 9 5 \% ~} \mathbf{C I})\end{array}$ & P-value \\
NICU morbidities & $0.90(0.82-0.99)$ & 0.03 \\
\hline Postmenstrual age (by week) & $0.86(0.80-0.93)$ & $<0.001$ \\
Birth weight (by I00 g) & $1.31(1.04-1.67)$ & 0.02 \\
Male gender & $0.97(0.76-1.24)$ & $0.8 \mathrm{I}$ \\
\hline
\end{tabular}

Abbreviations: $\mathrm{Cl}$, confidence interval; $\mathrm{NICU}$, neonatal intensive care unit. 
Table 62012 revised Portland patent ductus arteriosus management guidelines

Emphasize a careful physical exam with appreciation of PDA signs, symptoms, risk factors, and natural history. Continuity of care, with repeat exams and clinical assessment of respiratory support, is fundamental.

Emphasize noninvasive respiratory support using NCPAP. Continue fluid restriction advancing gradually up to $120-130 \mathrm{~mL} / \mathrm{kg} /$ day total fluids while the PDA is present.

Prophylactic use of indomethacin is contraindicated and early use at $<7$ days is usually unnecessary.

The indication for pharmacologic treatment is based upon a contextual amalgam of concerning or deteriorating parameters such as a more prominent murmur, lower diastolic blood pressure, bounding pulses, decreased perfusion, increasing apnea, increasing NCPAP, and/or fractional inspired oxygen, inability to wean or extubate, feeding intolerance, worsening radiograph, or pulmonary hemorrhage. Biomarkers such as B-natriuretic peptide are not acceptably predictive as yet, so are not recommended.

Obtain an echocardiogram if concerning signs and symptoms of the PDA are persisting despite conservative measures over time to help decide if pharmacologic or surgical treatment might be necessary.

A hemodynamically significant PDA generally means the diameter is $\geq 2-3 \mathrm{~mm}$ (although this is infant size dependent), with a left-to-rightshunt, AND significant left atrial and left ventricular enlargement. Consider indomethacin therapy (one course $=0.2 \mathrm{mg} / \mathrm{kg} \mathrm{IV} \mathrm{every}$ 12-24 hours $\times$ three doses) if the echocardiographic findings corroborate a significant PDA contribution to the clinical picture of concerning or deteriorating parameters.

There is insufficient data to recommend ibuprofen rather than indomethacin, but it can be used if a shortage of indomethacin exists.

Repeat echocardiography is recommended to help decide whether a second course of indomethacin is necessary (third course not recommended). Echocardiography is recommended at some point before discharge to examine PDAs that required pharmacologic closure therapy or if there are persistent signs of patency. Careful follow-up with cardiology is warranted in all PDAs still present at discharge.

Consider surgical ligation of the PDA if indomethacin is ineffective or contraindicated, and concerning clinical parameters persist.

Abbreviations: IV, intravenous; NCPAP, nasal continuous positive airway pressure; PDA, patent ductus arteriosus.

the impact of local culture (context + mechanism $=$ outcome), and observational trials such as the current study can be helpful in clinical dilemmas that lack RCTs because of high complexity or cost, lack of equipoise, and external validity questions. ${ }^{15,16}$ Davidoff goes further and states that there is a substantial moral element to QI, an ethical duty for physicians to balance individual patient safety with the overall community health needs in a fair and cost-effective manner that recognizes basic frameworks of epistemology. ${ }^{17}$

It is vital in QI projects to determine whether the recommended protocol and process of care was actually followed, rather than simply reporting outcomes. ${ }^{18}$ In the current study, the Era 2 PDA management could be seen as permissive and less aggressive, a reversal of many new NICU therapies over the past 30 years which generate enthusiasm (and expense) but later disappoint.7,19 Table 1 shows Era 2 to be notable for $67 \%$ fewer PDA infants receiving any indomethacin and, if given, was started $\sim 9$ days later, with fewer second courses administered. The surgical ligation rate trended downward and, if done, occurred $\sim 9$ days later. It is unlikely the modest $7 \%$ decrease in Day 1-28 total fluids had any beneficial effect. ${ }^{20}$ Even with consensus guidelines, there remained unmeasured physician variability recognizing, and (dis)comfort managing, chronic PDAs. It is biologically plausible that a sustained left-to-right shunt for weeks might increase the risk of CLD, ${ }^{21}$ and it was not quantified exactly how or when a clinician determined whether a PDA was "significant." There is concern with the increased CLD and Mortality after Day 7 or CLD, but reassurance is provided by the lack of increase in the adjusted risk of single or combination counts of the seven major VON morbidities (all weighted equally) in Era 2 (Table 5 and Figure 1). In Era 2, more infants were discharged home with a persistent PDA but the majority resolved spontaneously with no obvious ill effects; the need for outpatient coiling closure was similar between eras.

To improve outcomes, it is the authors' hope that by reemphasizing the importance of evaluating the PDA in a multivariable, contextual manner over time - with cyclooxygenase inhibitors or surgical ligation used judiciously - CLD and Mortality can be reduced and a favorable overall morbidity profile can be maintained (Table 6). Biomarkers such as B-type natriuretic peptide have not been used as yet, as definitive studies that demonstrate acceptable predictive value are waited upon. ${ }^{22}$ The authors agree with McNamara and Sehgal that sophisticated clinical and echocardiographic staging will likely prove valuable in helping to determine which PDAs are hemodynamically significant, and it is emphasized that the authors' amended guidelines (reformulated with cardiologists input; Table 6) are consistent with such staging. ${ }^{23}$ It is suspected that definitive RCTs are not forthcoming because of complex issues of customary therapy, equipoise, and expense.

Limitations of this investigation include the nonrandomized design, the lack of absolute strict adherence to the protocol, and incomplete measure of every variable that might affect PDAs - a common challenge with QI projects. The investigation did not determine the optimal strategy to manage the PDA and reduce overall NICU morbidity. However, this study had $100 \%$ participation of all very 
low birth weight infants with PDAs, something a consentrequiring RCT would not have achieved. The current study is easily the largest to date to employ a permissive PDA strategy and a wide spectrum of NICU therapies and outcomes were carefully documented. A definitive multicenter RCT is needed to define the optimal timing and method to treat symptomatic PDAs (and to clarify what "symptomatic" means). In the meantime, based on the Era 2 results, the authors plan to use the revised 2012 PDA guidelines (Table 6) and will scrutinize the resultant NICU outcomes using pragmatic QI methodology with the goal of reporting these Era 3 outcomes.

\section{Acknowledgments}

This investigation was supported by a grant from the Vollum Foundation and Northwest Newborn Specialists, PC. The authors wish to acknowledge Nicole Tipping, Catherine Tang, Nancy Dolphin, Amy Hollis, and Marceen Moe for their assistance with data collection.

\section{Disclosure}

The authors report no conflicts of interest in this work.

\section{References}

1. Vermont Oxford Network. Vermont Oxford Network Annual Report: Section 2, Table 2.5. Burlington, VT: Vermont Oxford Network; 2010.

2. Bose CL, Laughon MM. Patent ductus arteriosus: lack of evidence for common treatments. Arch Dis Child Fetal Neonatal Ed. 2007;92(6):F498-F502.

3. Benitz WE. Treatment of persistent patent ductus arteriosus in preterm infants: time to accept the null hypothesis? J Perinatol. 2010;30(4): 241-252.

4. Benitz WE. Patent ductus arteriosus: to treat or not to treat? Arch Dis Child Fetal Neonatal Ed. 2012;97(2):F80-F82.

5. Horbar JD, Rogowski J, Plsek PE, et al. Collaborative quality improvement for neonatal intensive care. Pediatrics. 2001;107(1):14-22.

6. Spear S, Bowen HK. Decoding the DNA of the Toyota production system. Harv Bus Rev. 1999;77(5):97-106.

7. Auerbach AD, Landefeld CS, Shojania KG. The tension between needing to improve care and knowing how to do it. New Engl J Med. 2007;357(6):608-613.
8. Walsh M, Laptook A, Kazzi SN, et al. A cluster-randomized trial of benchmarking and multimodal quality improvement to improve rates of survival free of bronchopulmonary dysplasia for infants with birth weights of less than 1250 grams. Pediatrics. 2007;119(5):876-890.

9. Payne NR, Finkelstein MJ, Liu M, Kaempf JW, Sharek PJ, Olsen S. NICU practices and outcomes associated with 9 years of quality improvement collaboratives. Pediatrics. 2010;125(3):437-446.

10. Institute of Medicine, Committee on Quality of Health Care in America. Crossing the Quality Chasm: A New Health System for the 21st Century. Washington, DC: National Academies Press; 2001.

11. Kaempf JW, Wu YX, Kaempf AJ, Kaempf AM, Wang L, Grunkemeier G. What happens when the patent ductus arteriosus is treated less aggressively in very low birth weight infants? J Perinatol. 2012;32(5):344-348.

12. Vermont Oxford Network. Manual of Operations for Infants Born in 2010: Release 14.0. Burlington, VT: Vermont Oxford Network; 2009. Available from: http://www.vtoxford.org/tools/2010ManualofOperatio nswithindex 14.pdf. Accessed February 1, 2013.

13. Sosenko IR, Fajardo MF, Claure N, Bancalari E. Timing of patent ductus arteriosus treatment and respiratory outcome in premature infants: a double-blind randomized controlled trial. J Pediatr. 2012;160(6): 929-935.

14. Van Cleave J, Dougherty D, Perrin JM. Strategies for addressing barriers to publishing pediatric quality improvement research. Pediatrics. 2011;128(3):e678-e686.

15. Berwick DM. The science of improvement. JAMA. 2008;299(10): 1182-1184.

16. Black N. Why we need observational studies to evaluate the effectiveness of health care. BMJ. 1996;312(7040):1215-1218.

17. Davidoff F. Systems of service: reflections on the moral foundations of improvement. BMJ Qual Saf. 2011;20(Suppl 1):i5-i10.

18. Chassin MR, Loeb JM, Schmaltz SP, Wachter RM. Accountability measures - using measurement to promote quality improvement. New Engl J Med. 2010;363(7):683-688.

19. Rauh SS, Wadsworth EB, Weeks WB, Weinstein JN. The savings illusion - why clinical quality improvement fails to deliver bottom-line results. New Engl J Med. 2011;365(26):e48.

20. De Buyst J, Rakza T, Pennaforte T, Johansson AB, Storme L. Hemodynamic effects of fluid restriction in preterm infants with significant patent ductus arteriosus. J Pediatr. 2012;161(3):404-408.

21. Clyman RI. Mechanisms regulating the ductus arteriosus. Biol Neonate. 2006;89(4):330-335.

22. Chen S, Tacy T, Clyman R. How useful are B-type natriuretic peptide measurements for monitoring changes in patent ductus arteriosus shunt magnitude? J Perinatol. 2010;30(12):780-785.

23. McNamara PJ, Sehgal A. Towards rational management of the patent ductus arteriosus: the need for disease staging. Arch Dis Child Fetal Neonatal Ed. 2007;92(6):F424-F427.
Research and Reports in Neonatology

\section{Publish your work in this journal}

Research and Reports in Neonatology is an international, peer-reviewed, open access journal publishing original research, reports, editorials, reviews and commentaries on neonatal health. The manuscript management system is completely online and includes a very quick and fair

\section{Dovepress}

peer-review system. Visit http://www.dovepress.com/testimonials.php to read real quotes from published authors. 